\title{
Work limitations, workplace concerns, and job satisfaction of persons with chronic disease
}

\author{
Andrew M.H. Siu ${ }^{\mathrm{a}, *}$, Anchor Hung ${ }^{\mathrm{b}}$, Ada Y.L. Lam ${ }^{\mathrm{a}}$ and Andy Cheng ${ }^{\mathrm{b}}$ \\ ${ }^{a}$ Department of Rehabilitation Sciences, The Hong Kong Polytechnic University, Hong Kong, China \\ ${ }^{\mathrm{b}}$ The Hong Kong Society for Rehabilitation, Hong Kong, China
}

\begin{abstract}
.
INTRODUCTION: This study investigates the workplace experiences of people with chronic diseases, including their work limitations, emotional health, concerns about discrimination, and support from colleagues and employer. This study identifies the factors that contribute to work adjustment (job tenure and job satisfaction).

METHODS: A purposive sample of 136 persons aged 18 to 60 with chronic diseases who had been employed in the past 6 months completed a survey about their workplace experience. The questionnaire included several standardized instruments: the Perceived Health and Self-efficacy in Managing Chronic Disease Scale, Work Limitations Questionnaire, Overall Job Satisfaction Scale, and the Depression Anxiety Stress Scale-21. The researchers also designed original items to measure concerns about discriminatory practices, workplace support, and self-stigma.

RESULTS: Persons with chronic diseases were fairly satisfied with their jobs and had extended stays in those jobs. They reported a minor productivity loss and physical limitations. Most participants let co-workers, employers, and supervisors know they had chronic disease, but they were concerned about the support those people provide. Participants were more likely to be highly satisfied with their jobs if they had high self-efficacy in managing their disease, perceived more workplace support, and had less work limitations (especially output demands). Job tenure is associated age, education, and monthly income, but not clinical indicators.

CONCLUSIONS: Persons with chronic disease who were able to maintain good work adjustment tended to be "fit" with few work limitations and little emotional distress. The key factors affecting work adjustment were efficacy in managing their disease, workplace support, and output demands.
\end{abstract}

Keywords: Work limitations, job satisfaction, chronic disease, Chinese

\section{Introduction}

Chronic diseases - such as cardiovascular diseases, chronic respiratory diseases, diabetes, and cancer - are some of the major causes of ill health, disability, and death around the world. In Hong Kong, "persons with chronic diseases" refers to people who require long-

${ }^{*}$ Corresponding author: Dr. Andrew M. H. Siu, Department of Rehabilitation Sciences, The Hong Kong Polytechnic University, Hunghom, Kowloon, Hong Kong, China. Tel.: +852 27666753; E-mail: a.siu@polyu.edu.hk. term (i.e., lasting at least 6 months) medical treatment and consultation. A recent government survey showed that there are more than 1.1 million persons with chronic disease in Hong Kong, constituting about $16.7 \%$ of the total population [1]. Although $58.8 \%$ of persons with chronic diseases are 60 years and over, there is still a large portion in other adult age groups that are likely to go to work.

Chronic diseases often last a lifetime. Their slow progression can increase the stresses and burdens to individuals, their families, and society [2]. Chronic diseases can impact psychological adjustment and social 
adaptation [3], gradually interfering with daily activities and decreasing people's ability to function in society [4]. While many people with chronic disease continue to go to work, their unemployment rate is higher than persons without disease.

On top of the stresses of work life, persons with chronic disease often face additional challenges, such as discrimination, lower wages than similar workers, and a lack of accommodation and support in the work environment. Physical discomfort, pain, fatigue, or disease complications can hamper their effectiveness at work.

Nevertheless, a large proportion of persons with chronic disease can and do go to work. Many can contribute to the finances of their family and the productivity of society. In Hong Kong, most vocational rehabilitation services are designed for persons with intellectual, psychiatric, or physical disabilities. There are very few such services specifically designed for people with chronic diseases. Similarly, few studies have examined the needs and concerns of persons with chronic disease in the workplace. In this study, we examine these concerns in three areas: (1) work limitations, (2) workplace concerns (e.g., discriminatory practices and employer support), and (3) job satisfaction and job tenure.

First, persons with chronic disease face a wide range of work limitations varying with different diseases. For example, more than half of people with angina report at least some difficulty in performing physically exerting tasks, handling stressful situations, and accomplishing tasks at work [5]. Persons with rheumatoid arthritis report significant work limitations in physical, mental, output, and management demands, decreasing productivity and increasing work hours to compensate for the loss of productivity [6,7].

Studies of work limitations of persons with chronic diseases in Chinese populations are scarce. One notable exception is a study on the impact of Systemic Lupus Erythematosus (SLE) on work capacity [8]. The study found that fatigue and musculoskeletal pain were the most important factors leading to job loss and work limitations. Factors that affected job mastery included pain, anxiety, depression, emotional responses to the chronic nature of the disease, and adjustment to the disability [4]. Given the scarcity of studies in Chinese populations, one of the goals of this study is to test whether work limitations manifest themselves differently in Chinese populations and whether there are differences in work limitations among diagnostic groups.

Second, many have studies shown that persons with disabilities and diseases often face discrimination [9].
That discrimination includes demotion, loss of employment, loss of benefits, changes in the terms of employment, and lack of accommodation [10]. Employer discrimination is one of the key factors affecting the work performance and job tenure of persons with chronic disease. Discrimination also takes a psychological toll. Persons with chronic diseases often worry that they will face discrimination, stigma, and less employer support if they tell their employers about their medical condition. Therefore, many persons with chronic diseases conceal their disease and try to make their functional limitation less visible [11]. Some fear gossip; some fear being fired; and some fear the negative effects of their disclosure on career $[12,13]$. But from employers' perspective, they worry about sick leave, the need to make accommodations, and the extra costs involved in hiring a person with chronic disease [14], although some employers consider it a social responsibility to hire people with chronic disease [15].

Third, this study focuses on whether chronic disease can decrease job satisfaction and what specific elements of chronic disease affect their job tenure. Job tenure, i.e. how long people stay in their job, is a function of their job satisfaction and their capacity to meet the job requirements (job mastery) [16]. Many studies have found that aspects of job mastery are good predictors of tenure: ability to get the job done, fit into the workplace, learn the ropes, get along with others, and plan their career path [10]. However, there are few studies in Chinese populations looking at how job mastery, job satisfaction, work limitations, and emotional health influence job tenure for persons with chronic disease.

We hypothesize that several variables are closely related to job satisfaction and job tenure of persons with chronic disease. These variables include experienced work limitations, perceived physical and emotional health, self-efficacy in managing disease, and workplace concerns (including disclosure of disease and support from colleagues and employer). This study measures these variables and then uses them to predict job tenure and job satisfaction.

\section{Method}

\subsection{Objectives}

The study examines the experience, needs, and concerns of persons with chronic disease in the workplace. There are four main objectives: (1) examine work limitations of persons with chronic diseases; (2) examine 
common workplace concerns for persons with chronic diseases, including discrimination practices, disease disclosure, self-stigma, and employer and social support; (3) examine the psychological well-being, job satisfaction, and job tenure of persons with chronic diseases who are employed; and (4) identify the key factors related to the work adjustment (job satisfaction and job tenure) of persons with chronic disease.

\subsection{Participants}

The participants were recruited using purposive sampling through community-based rehabilitation centers in three districts of Hong Kong. To be included, participants had to be: (1) adults aged 18 to 60, (2) employed part-time or full-time (including job placements) or have worked in the past 6 months, (3) educated through primary school (Grade 7), (4) diagnosed with chronic disease(s), (5) able to read or understand Chinese. Participants were excluded if they: (1) were self-employed or an employer, (2) had cognitive disabilities or communication difficulties that limit their understanding of the questionnaire or the expression of their opinion.

To run an effective multiple regression, the analysis needs a fairly large sample size. Using the sample size estimation software PASS [17], it was calculated that this study would need 152 participants in order to have adequate power for a regression analysis with 5 predictors, with the standard 0.80 power requirement and an $\alpha$ of 0.05 .

\subsection{Procedure}

Three community-based rehabilitation centers helped recruit participants. Ethics approval had been obtained from both the university and the community rehabilitation centers. Research staff extracted a database of 400 clients and members of the rehabilitation centers who reported that they had been working. Research assistants and clerical staff at the centers then contacted these potential participants and phone to invite them to participate in the study. Upon obtained their informed verbal consent, we would send them a hard copy of the research questionnaire by mail. The participants were requested to return the completed questionnaire and written consent form for participation using a businessreply envelope addressed to the community rehabilitation centers. A telephone reminder for return of questionnaire was sent 4 weeks after the questionnaire was sent.

\subsection{Instruments}

A 97-item self-completed questionnaire was designed by incorporating translated Chinese versions of the Perceived Health and Self-efficacy in Managing Chronic Disease Scale [18], Work Limitations Questionnaire, Overall Job Satisfaction Scale, and Depression Anxiety Stress Scale-21 [19,20]. These standardized instruments measure work limitations, job satisfaction, self-efficacy in managing disease, and emotional health. Based on a review of previous studies, we also designed questions about job tenure, working conditions, and workplace concerns (disclosure about disease, discrimination, support, and self-stigma).

\subsubsection{Work limitations}

Work limitations were measured using the Work Limitations Questionnaire (WLQ) [21], a 25-item selfcompleted questionnaire designed for people with disease or disabilities. The work limitations are categorized in the four subscales of Time Demands, Physical Demands, Mental-Interpersonal Demands, and Output Demands. The WLQ has high internal consistency. The WLQ subscales predicted a significant proportion of variation in persons with disabilities' perceived health (measured by the SF36) [21]. This study used a Chinese version that was translated and developed in Taiwan.

\subsubsection{Workplace concerns}

Based on previous studies on workplace discrimination [10,11], we created 16 questionnaire items (in Chinese) to measure the following concerns of workers with chronic diseases: (1) concerns about discrimination practices, (2) emotional and practical support, and (3) self-stigma. An exploratory factor analysis of the 16 items showed that three factors explained $56.61 \%$ of total variance (Table 1). We labeled the three factors discrimination, self-stigma, and support according to the items, which were consistent with the original theory for writing up the items. The item "I think I should tell my employer and colleagues that I have chronic disease" was dropped from further analysis because it loaded significantly on two factors.

\subsubsection{Managing chronic disease}

To measure how well participants managed chronic disease, we used several items from the scales developed by Lorig, Stewart, Ritter, Gonzalez, Laurent, and Lynch [18]. Two 10-point items ranging from no to severe were used to measure pain and fatigue, and 
Table 1

Principal component analysis ${ }^{1}$ on items of workplace concerns

\begin{tabular}{|c|c|c|c|}
\hline \multirow[t]{2}{*}{ Items $^{2}$} & \multicolumn{3}{|c|}{ Component $^{3}$} \\
\hline & 1 & 2 & 3 \\
\hline 13. If I were to tell my colleagues/supervisor that I have chronic disease, I worry it would affect my career. & 0.82 & 0.28 & 0.05 \\
\hline 6. I worry that if colleagues know that I have chronic disease, they would see me as less capable at work. & 0.81 & 0.27 & -0.02 \\
\hline 1. I worry that I will not be treated fairly because of my disease. & $\overline{0.75}$ & 0.30 & 0.02 \\
\hline 4. I don't want colleagues to learn that I have chronic disease, so that they will not discriminate against me. & $\overline{0.75}$ & 0.15 & -0.39 \\
\hline $\begin{array}{l}\text { 3. I don't want colleagues to learn that I have chronic disease, as I don't want them to take pity on me or be } \\
\text { too concerned about me. }\end{array}$ & $\overline{0.72}$ & 0.05 & -0.32 \\
\hline 9. It is not easy for others to accept me, with this kind of disease. & $\underline{0.67}$ & 0.27 & -0.17 \\
\hline 11. I have experienced discrimination at work because of my disease. & $\overline{0.65}$ & 0.36 & 0.01 \\
\hline 5. I think I should tell my employer and colleagues that I have chronic disease. & $-\overline{0.55}$ & 0.03 & $\underline{0.53}$ \\
\hline 14. I feel some people become unnatural when I am around. & $\overline{0.07}$ & $\underline{0.82}$ & $-\overline{0.04}$ \\
\hline 15. I feel that some people treat me as somebody with lower ability. & 0.25 & $\overline{0.78}$ & 0.08 \\
\hline 16. I feel some people tend to avoid getting close to me. & 0.20 & $\overline{0.74}$ & -0.13 \\
\hline 12. People can easily tell I have chronic disease from my appearance & 0.27 & $\overline{0.35}$ & 0.07 \\
\hline 8. Although I have chronic disease, I can do my job well. & -0.07 & $-\overline{0.26}$ & 0.06 \\
\hline $\begin{array}{l}\text { 10. I tell colleagues/employer that I have chronic disease, because I want them to be more considerate and } \\
\text { supportive. }\end{array}$ & 0.20 & $\overline{0.02}$ & 0.79 \\
\hline 2. Colleagues are willing to support me, with chronic disease. & -0.47 & -0.24 & 0.54 \\
\hline 7. My supervisor or employer is willing to provide assistance and support to me because of my disease. & -0.40 & -0.07 & $\overline{0.51}$ \\
\hline Variance Explained & 29.62 & 15.93 & $1 \overline{1.06}$ \\
\hline$\alpha$ & 0.90 & 0.63 & 0.53 \\
\hline
\end{tabular}

${ }^{1}$ Varimax rotation was used.

${ }^{2}$ These are English translations of the original items, which were written in Chinese.

${ }^{3}$ Suggested labels for the three factors are: (1) concerns about discrimination, (2) self-stigma, and (3) social support.

a 5-point item was used to measure general perceived health. Six items measured self-efficacy in managing the physical and emotional effects of disease. These scales were previously translated and used in an evaluation study of a chronic disease self-management program [22].

\subsubsection{Psychological well-being}

The DASS-21, a simplified version of full edition DASS-42, was used to measure the three emotional states of depression, anxiety, and tension/stress ( 7 items for each section) $[18,19]$. Participants were asked to rate the extent to which they had experienced each state over the past week on a 4-point scale. Test-retest reliability of the DASS subscales is adequate to good (ICC $=0.71$ for the depression scale, 0.79 for anxiety, and 0.81 for stress). The DASS depression scale has been shown to correlate strongly with the BDI-II $(r=0.74)$; the DASS anxiety scale has been shown to correlate highly with the BAI $(r=0.81)$ [23,24].

\subsubsection{Work adjustment}

Job satisfaction and job tenure were the two variables used to indicate work adjustment. We used the 6-item version of the Overall Job Satisfaction Scale (OJSS) to measure overall job satisfaction [25]. Both the 18-item and 6-item versions of the OJSS were found to be unidimensional measures with good reliability. For job tenure, we asked participants to report on the percentage of time employed in the past two years and length of stay in the present job (or last job).

\section{Results}

A total of 157 questionnaires were returned by mail or through the rehabilitation centers, and 136 met the inclusion criteria. Twenty-one respondents were not included because they were over age 60 , self-employed, or employers themselves. The valid response rate to the survey was $34 \%$. Around half of respondents were male $(52.1 \%)$, and the median age group was 45 to 54. They had an average of 9.5 years of education (SD $=3.0$ ), and most $(74.3 \%)$ were married. The most common primary diagnoses were cardiovascular disease $(22.2 \%)$, diabetes $(19.3 \%)$, rheumatoid arthritis (19.1\%), SLE $(8.1 \%)$, chronic pain $(5.9 \%)$, hypertension $(5.1 \%)$, epilepsy $(4.4 \%)$, and stroke $(3.7 \%)$. On average, they had had the disease for 9.9 years $(\mathrm{SD}=$ 7.4). Most of the participants had one (47.1\%), two $(40.7 \%)$, or three $(8.9 \%)$ types of chronic diseases, for an average of $1.7(\mathrm{SD}=0.81)$ chronic diseases. The number of diseases they had correlated significantly with the pain $(r=0.27, p<0.01)$ and fatigue $(r=$ $0.19, p=0.03$ ) they experienced, but not with overall health condition or work limitations (WLQ score). 
Table 2

\begin{tabular}{|c|c|c|c|c|c|}
\hline Variables & $N$ & M & SD & Min. & Max. \\
\hline \multicolumn{6}{|l|}{ Demographic } \\
\hline Years of education & 129 & 9.53 & 2.97 & 0.00 & 14 \\
\hline Years with disease & 132 & 9.89 & 7.38 & 1.00 & 38.00 \\
\hline Monthly income (US\$) & 109 & 1798 & 1351 & 192 & 7692 \\
\hline \multicolumn{6}{|l|}{ Health-related } \\
\hline Health condition & 135 & 3.64 & 0.71 & 1.00 & 5 \\
\hline Fatigue & 136 & 5.77 & 2.17 & 0.00 & 10 \\
\hline Pain & 134 & 3.96 & 2.76 & 0.00 & 10 \\
\hline Self-efficacy in managing disease & 136 & 6.29 & 2.04 & 2.50 & 10.00 \\
\hline \multicolumn{6}{|l|}{ Workplace concerns } \\
\hline Support & 136 & 3.34 & 0.58 & 1.60 & 4.80 \\
\hline Discrimination & 136 & 2.84 & 0.79 & 1.00 & 4.75 \\
\hline Self-stigma & 135 & 1.61 & 0.56 & 1.00 & 3.67 \\
\hline \multicolumn{6}{|l|}{ Work limitations } \\
\hline Time management scale & 133 & 14.06 & 15.24 & 0.00 & 65.00 \\
\hline Physical demands scale & 136 & 35.61 & 25.97 & 0.00 & 100.00 \\
\hline Output demands scale & 134 & 16.20 & 15.81 & 0.00 & 85.00 \\
\hline Mental interpersonal scale & 136 & 15.20 & 16.51 & 0.00 & 66.67 \\
\hline WLQ index & 131 & 0.05 & 0.04 & 0.00 & 0.18 \\
\hline Productivity loss index & 131 & 4.94 & 3.57 & 0.00 & 16.40 \\
\hline \multicolumn{6}{|l|}{ Emotional issues (DASS) } \\
\hline Stress subscale & 136 & 0.82 & 0.63 & 0.00 & 3.00 \\
\hline Anxiety subscale & 136 & 0.56 & 0.53 & 0.00 & 3.00 \\
\hline Depression subscale & 136 & 0.55 & 0.60 & 0.00 & 2.71 \\
\hline \multicolumn{6}{|l|}{ Work adjustment } \\
\hline Job satisfaction & 135 & 3.61 & 0.75 & 2.00 & 5.00 \\
\hline Job tenure (months) & 133 & 134.52 & 121.25 & 1.00 & 480.00 \\
\hline
\end{tabular}

Most of the participants described their general health as average (59.3\%) or good (28.9\%). They were moderately confident in being able to manage their disease ( $M=6.30, S D=2.04$, on a scale from 1 to 10$)$. Fatigue was a more significant problem $(\mathrm{M}=5.77, \mathrm{SD}$ $=2.17$, on a scale from 1 to 10$)$ than pain $(\mathrm{M}=3.96$, $\mathrm{SD}=2.76$ ). Out of a scale from 0 to 3 , most respondents did not experience much stress $(\mathrm{M}=0.82, \mathrm{SD}=$ $0.63)$, anxiety $(\mathrm{M}=0.56, \mathrm{SD}=0.05)$, or depression $(\mathrm{M}=0.55, \mathrm{SD}=0.06)$.

Most of the participants had a full-time job (83.8\%), and the rest had a part-time job (16.2\%). They had stayed in their present job for an average of 11.2 years $(\mathrm{SD}=10.10)$. Their average income was HK $\$ 14,026.91$ (approximately US $\$ 1,798$ ) per month $(\mathrm{SD}=10,540.01)$. Most of the respondents let their work supervisors $(67.5 \%)$ and colleagues $(74 \%)$ know that they have chronic disease. The participants who had disclosed to their colleagues (but not necessarily employers) that they have chronic diseases had significantly longer job tenure than those who had not $(t=$ $2.7, p=0.008$ ).

Participants were more concerned with emotional and social support $(\mathrm{M}=3.34, \mathrm{SD}=0.58)$ than discriminatory practices $(\mathrm{M}=2.84, \mathrm{SD}=0.79)$ in the workplace. Self-stigma was uncommon $(\mathrm{M}=1.61$,
$\mathrm{SD}=0.56$, out of a scale of 1 to 4$).$ The respondents were fairly satisfied with their jobs $(\mathrm{M}=3.61, \mathrm{SD}=$ 0.75 , on a scale from 1 to 5 ).

The WLQ gave a work limitations score of 0.05 (SD $=0.04$ ), with a Productivity Loss Index of 4.94\% (SD $=3.57$; Table 2). Participants reported more limitations in coping on the Physical Demands scale ( $\mathrm{M}=35.61$, $\mathrm{SD}=25.97)$, than on the Time Management scale (M $=14.06, \mathrm{SD}=15.24)$, Mental-Interpersonal Demands scale $(\mathrm{M}=15.20, \mathrm{SD}=16.51)$, or Output Demands scale $(M=16.20, S D=15.81)$. There were no significant differences in work limitations between participants with the key primary diagnoses of cardiovascular disease, diabetes, rheumatoid arthritis, SLE (when $n>10$ ). The groups with $n<10$ are participants with depression ( $n=2,14.7 \%$ loss), epilepsy ( $n=6,8.6 \%$ loss), multiple sclerosis ( $n=4,6.5 \%$ loss), and stroke ( $n=4,6.1 \%$ loss). Those with hypertension $(n=7)$ tended to have the smallest productivity loss $(2.4 \%)$. There were no significant differences in WLQ overall or subscale scores between sexes or between full- and part-time workers.

Job satisfaction correlated significantly with age $(r=0.34, p<0.01)$ and years of having disease $(r=-0.14, p<0.05)$, but not with monthly income and years of education (Table 3 ). Job satisfaction 
Table 3

Correlations between predictors and work adjustment variables (job satisfaction and job tenure)

\begin{tabular}{lcc}
\hline Variables & Job satisfaction & Job tenure (months) \\
\hline Demographic & & $0.34^{* *}$ \\
Age & -0.06 & $-0.13^{* *}$ \\
Years of education & $-0.14^{*}$ & -0.12 \\
Years of having disease & 0.08 & $0.28^{* *}$ \\
Monthly income & & -0.06 \\
Health-related & $-0.26^{* *}$ & -0.04 \\
Perceived health & $-0.29^{* *}$ & 0.03 \\
Fatigue & $-0.31^{* *}$ & 0.01 \\
Pain & $0.48^{* *}$ & $-0.23^{*}$ \\
Self-efficacy in managing disease & & -0.01 \\
Workplace concerns & $-0.39^{* *}$ & 0.12 \\
Discrimination & $-0.45^{* *}$ & -0.07 \\
Self-stigma & $0.33^{* *}$ & 0.04 \\
Support & & -0.05 \\
Work limitations & $-0.35^{* *}$ & -0.10 \\
Time management scale & $-0.15^{*}$ & -0.07 \\
Physical demands scale & $-0.34^{* *}$ & -0.07 \\
Output demands scale & $-0.36^{* *}$ & -0.06 \\
Mental interpersonal scale & $-0.39^{* *}$ & -0.03 \\
WLQ Index & $-0.39^{* *}$ & -0.03 \\
Productivity loss index & &
\end{tabular}

Note. Kendall's $\tau$ was reported. ${ }^{*} p<0.05,{ }^{* *} p<0.01$.

correlated significantly with most of the health-related variables (perceived health, fatigue, and pain, with $r \mathrm{~s}$ ranging from -0.26 to $0.31, p<0.01$ ), self-efficacy in managing disease $(r=0.48, p<0.01)$, workplace concerns (discrimination, self-stigma, and support; $r \mathrm{~s}$ ranging from 0.33 to $-0.45, p<0.01$ ), aspects of work limitations ( $r$ s ranging from -0.15 to $-0.39, p<$ 0.05 ), and emotional health ( $r$ s ranging from -0.33 to $-0.45, p<0.01)$. But job tenure only correlated significantly with age $(r=0.25, p<0.01)$, years of education $(r=-0.13, p<0.05)$, monthly income $(r=$ $-0.28, p<0.01)$, and concerns about discrimination $(r=-0.23, p<0.05)$.

Demographic, health-related concerns, workplace concerns, work limitations (WLQ Score only), and emotional health were used to predict job satisfaction and job tenure (Tables 4 and 5). Stepwise multiple regression $\left(\mathrm{R}^{2}=0.57\right.$, adjusted $\left.\mathrm{R}^{2}=0.55\right)$ found that age $(\beta=0.25, p<0.001)$, self-efficacy in managing disease $(\beta=0.48, p<0.001)$, workplace support $(\beta=0.22, p<0.001)$, and WLQ score $(\beta=-0.17$, $p=0.03$ ) were good predictors of job satisfaction (Table 4). When we used four WLQ subscales as predictors in the regression analysis (instead of the overall WLQ alone), the Output Demands scale (but not the other three scales) was a significant predictor of job satisfaction $(\beta=-0.17, p=0.02)$. The clinical and health-related variables failed to predict the job tenure of respondents $\left(\mathrm{R}^{2}=0.35\right.$, adjusted $\left.\mathrm{R}^{2}=0.32\right)$; only monthly income $(\beta=0.50, p<0.001)$, age $(\beta=0.25$, $p=0.01)$, and years of education $(\beta=-0.26, p=$ 0.02 ) were important predictors (Table 5).

\section{Discussion}

Most of the participants worked full time and had one of five types of chronic disease (cardiovascular disease, diabetes, SLE, rheumatoid arthritis, and chronic pain). They had a wide range of jobs and monthly income. More than two-thirds of the participants had let their supervisors and/or colleagues know they have chronic disease. They are largely satisfied with their jobs and have stayed in their jobs for a long time. This reflects the fact that the participants belong to a "fit" group of persons with chronic disease that remain competitive in the job market.

This "fit" group of participants had few work limitations and a small productivity loss of around 5\%. They have relatively more difficulty coping with physical demands than other aspect of work limitations, and fatigue is the most significant way their disease affects their 
Table 4

Results of stepwise multiple regression predicting job satisfaction

\begin{tabular}{lrrrrc}
\hline Variables & $b$ & SE & $\beta$ & \multicolumn{1}{c}{$t$} & $p$ \\
\hline Self-efficacy in managing disease & 0.18 & 0.03 & 0.48 & 5.87 & $<0.001$ \\
Age & 0.19 & 0.06 & 0.25 & 3.29 & $<0.001$ \\
Support & 0.23 & 0.07 & 0.22 & 3.09 & $<0.01$ \\
Work Limitation Questionnaire (WLQ) sum score & -3.54 & 1.63 & -0.17 & -2.18 & 0.03 \\
\hline
\end{tabular}

Note. $\mathrm{R}^{2}=0.57$, adjusted $\mathrm{R}^{2}=0.55, \mathrm{SEE}=0.50$

Table 5

Results of stepwise multiple regression in predicting job tenure (length of stay in present job)

\begin{tabular}{lrrrrc}
\hline Variables & $b$ & \multicolumn{1}{c}{ SE } & $\beta$ & \multicolumn{1}{c}{$t$} & $p$ \\
\hline Monthly income & 0.01 & 0.00 & 0.50 & 5.08 & $<0.001$ \\
Age & 31.64 & 12.46 & 0.25 & 2.54 & 0.01 \\
Years of education & -11.56 & 4.83 & -0.26 & -2.40 & 0.02 \\
\hline
\end{tabular}

Note. $\mathrm{R}^{2}=0.35$, adjusted $\mathrm{R}^{2}=0.32, \mathrm{SEE}=103.59$

work performance. They tend to manage their health and disease quite well, and emotional issues were uncommon. These results could imply that only persons with chronic disease who have few work limitations, are capable of maintaining their health, and can continue to stay employed. A possible alternative explanation is that the participants who have more limitations and less satisfactory adjustment may have been screened out in the recruitment process of this study (particularly by not having been employed in the past 6 months).

In comparing work limitations among groups with different diagnoses, we did not find major differences between groups with more than 15 participants (i.e., cardiovascular disease, diabetes, and rheumatoid arthritis). Work limitations and productivity loss can result from a complex interaction of the nature of the disease, treatment, self-management efforts, and employment conditions. Diagnoses could be one of the many factors that may contribute to work limitations, and indeed persons with the same diagnosis could have very different functional level or work capacity.

In general, the participants had satisfactory work adjustment, indicated by their high job satisfaction and long job tenure (over 11 years). However, none of the health-related, clinical, or work limitation variables were useful predictors of job tenure. Those with longer job tenure tended to be older, have fewer years of education, and have a higher monthly income. The variance accounted for by these variables was not high (32\%), and it is likely that there are other important predictors that were not measured in our model. This also implies that job tenure is quite independent of the presence of work limitations, health condition, work stress, and workplace concerns.

Job satisfaction, as the other indicator of work adjustment, was predicted by age, self-efficacy in man- aging the disease, workplace support, and work limitations. The regression model accounted for a significant percentage of the variance in job satisfaction (55\%), meaning that those who are older, those who have higher self-efficacy in disease management, those who experience more workplace support, and those who have less work limitations are more likely to be satisfied in the workplace.

This finding has several implications. First, it is important to assist persons with chronic diseases to build up their self-efficacy [3,25]; this is the objective of most self-management programs. Second, work limitations significantly influenced job satisfaction. On further analysis, the Output Demands subscale (which is mainly based on being able to handle workload effectively in spite of having chronic disease) was a valid predictor of job satisfaction. However, when compared to the other subscales (Time Management, Physical, and Mental-Interpersonal), Output Demands is less likely to be within the control of workers, as it may be imposed by the work environment and changing job requirements. Third, workplace support is a significant predictor of job satisfaction. This refers to the experience of being supported by colleagues, supervisors, and employers, even though they know the person has chronic disease. Such a supportive environment is what persons with chronic diseases see as most important. Building such an atmosphere surely requires the joint effort of the person with chronic disease, colleagues, and the employer.

The results of this study have a number of implications for the development of community-based services in support of persons with chronic diseases in the workplace. First, rehabilitation professionals should help clients manage fatigue and health conditions, helping 
them build up self-efficacy and self-management behaviors. Second, professionals should identify work limitations together with clients and discuss how to disclose their disease or limitations to people in the workplace and how to solicit support and reasonable accommodations (such as in output demands). Furthermore, professionals could educate clients about discrimination practices and how they could be handled in the workplace.

\section{Conclusion}

This study explored and highlighted the workplace concerns of persons with chronic disease. The persons with chronic disease in this study were fairly satisfied with their jobs, and they had extended stays in their job (most continued to stay in their jobs after onset of their disease). Participants reported a small productivity loss (around 5\%), with physical limitations being the key difficulty. Most participants let co-workers (but not always employers/supervisors) know about their disease. They are concerned with workplace support provided by colleagues and employers. Persons with chronic diseases who are older, have a higher self-efficacy in managing their disease, perceive more workplace support, and have less work limitation (especially in output demands) are likely to have high job satisfaction. Job tenure of the participants was associated with their age, education, and monthly income, but not with clinical or functional indicators. This implies that job tenure depends on many other factors that are not health-related or clinical. The results implied that persons with chronic disease who can maintain good work adjustment make up a "fit" group that experience few work limitations and little emotional distress. High efficacy in managing their disease, good workplace support, and reasonable output demands were the key factors affecting their work adjustment.

\section{References}

[1] Census and Statistics Department. Persons with disabilities and chronic diseases in Hong Kong. Feature Articles of HKMDS 2009. 2009 Feb 20 [cited 2009 Feb 24]. Available from: http://www.censtatd.gov.hk/products_and_services/products/ publications/statistical_report/feature_articles/health/index_ cd_B70902FC_dt_detail.jsp.

[2] Kane RL. Chronic care: The unmet challenge. Asian J Gerontol Geriatr. 2006; 1: 26-30.

[3] Lorig K, Holman HR, Sobel D, Laurent DD, Gonzalez VM, Minor M. Living a healthy life with chronic conditions. Palo Alto, CA: Bull Publishing Company, 2006.
[4] Bishop M. The recovery process and chronic illness and disability: Applications and implications. J Vocat Rehabil. 2001; 16: 47-52.

[5] Lerner DJ, Amick BC, Malspeis S, Rogers WH, Gomes DR, Salem. The angina-related limitations at work questionnaire. Qual Life Res. 1998; 7: 23-32.

[6] Crockatt ST, Targett P, Cifu D, Wehman P. Return to work of individuals with arthritis: A review of job performance and retention. J Vocat Rehabil. 2009; 30: 121-131.

[7] Walker N, Michaud K, Wolfe F. Work limitations among working persons with Rheumatoid Arthritis: Results, reliability, and validity of Work Limitations Questionnaire in 836 patients. J Rheumatol. 2004; 32: 1006-12.

[8] Mok CC, Cheung MY, Ho LY, Yu KL, To CH. Risk and predictors of work disability in Chinese patients with systemic lupus erythematosus. Lupus. 2008; 17: 1103-07.

[9] McMahon BT, Shaw LR. Workplace discrimination and disability. J Vocat Rehabil. 2005; 23: 137-43.

[10] Rumrill P, Roessler R, Vierstra C, Hennesstey M, Staples L. Workplace barriers and job satisfaction among employed people with multiple sclerosis: An empirical rationale for early intervention. J Vocat Rehabil. 2004; 20: 177-83.

[11] Allen S, Carlson G. To conceal or disclose a disabling condition? A dilemma of employment transition. J Vocat Rehabil. 2003; 19: 19-30.

[12] Mount D, Johnstone B, White C, Sherman A. Vocational outcomes: VR service determinants for persons with epilepsy. J Vocat Rehabil. 2005; 23: 11-20.

[13] Stewart DE, Cheung AM, Duff S, Wong F, McQuestion M, Cheng $\mathrm{T}$, et al. Long-term breast cancer survivors: confidentiality, disclosure, effects on work and insurance. Psychooncol. 2001; 10: 259-63.

[14] Munir F, Pryce J, Haslam C, Leka S, Griffiths A. Gender differences in managing chronic illness at work: Exploring predictors for disclosure. J Vocat Rehabil. 2006; 25: 173-80.

[15] Hernandez B, Keys C, Balcazar F. Employer attitudes toward workers with disabilities and their ADA employment rights: A literature review. Journal of Rehabil. 2000; 66: 4-16.

[16] Dawis R. Person-environment-correspondence theory. In: Duane Brown and Associates, editors. Career choice and development. San Francisco: Jossey Bass, 2002, p. 427-464.

[17] Hintze, J. (2008). PASS 2008. NCSS, LLC. Kaysville, Utah, USA. www.ncss.com.

[18] Lorig K, Stewart A, Ritter P, Gonzalez V, Laurent D, Lynch J. Outcome measures for health education and other health care interventions. Thousand Oaks: Sage, 1996.

[19] Lovibond SH, Lovibond PF. Manual for the Depression Anxiety Stress Scales. 2nd ed. Sydney: Psychology Foundation, 1995.

[20] Taouk M, Lovibond PF, Laube R. Psychometric properties of a Chinese version of the short Depression Anxiety Stress Scales (DASS-21). Report for New South Wales Transcultural Mental Health Centre. Sydney: Cumberland Hospital, 2001.

[21] Lerner DJ, Benjamin C, Amick III, Rogers WH, Malspeis $\mathrm{S}$, Bungay $\mathrm{K}$, et al. The work limitations questionnaire. Med Care. 2001; 39: 72-85.

[22] Siu AMH, Chan CCH, Poon PKK, Chui DYY, Chan SCC. Evaluation of the chronic disease self-management program in a Chinese population. Patient Educ Couns. 2007; 65: 42-50.

[23] Lovibond SH, Lovibond PF. The structure of negative emotional states: Comparison of the depression anxiety stress scales (DASS) with the Beck depression and anxiety inventories. Behav Res Ther. 1995; 33: 335-43. 
[24] Brown TA, Korotitsch W, Chorpita BF, Barlow DH. Psychometric properties of the Depression Anxiety Stress Scales (DASS) in clinical samples. Behav Res Ther. 1997; 35: 79-89.

[25] Agho AO, Mueller CW, Price JL. Discriminant validity of measures of job satisfaction, positive affectivity and negative affectivity. J Occup Organ Psych. 1993; 46: 1007-1020.

[26] Siu AMH, Chan CCH, Poon PKK, Chui DYY, Chan SCC. Evaluation of the chronic disease self-management program in a Chinese population. Patient Educ Couns 2007; 65: 42-50. 